\title{
Original Article BENEFITS OF CERVICAL CERCLAGE TO IMPROVE PREGNANCY OUTCOME IN CERVICAL INCOMPETENCE
}

\author{
Anjuman Ara', Sanjida Khan ${ }^{2}$, Mahbuba Akhter ${ }^{3}$, Eshrat Jahan ${ }^{4}$, Mohammad Anwarul Hassan $^{5}$, \\ Fahmida Khanam ${ }^{6}$
}

\begin{abstract}
Background: To determine ability of cervical cerclage to improve pregnancy outcome in patients having cervical incompetence.

Methods: A retrospective study was conducted at Central Hospital Limited, Dhanmondi, Dhaka on 35 patients. All had history of one or more mid trimester abortion and were subjected to cervical cerclage (McDonald suture).

Results: Average pregnancy prolongation was 17 weeks. Just over half of these women (51\%) delivered at term and just over half the newborns (51\%) weighed above $2.5 \mathrm{~kg}$. Over $11 \%$ had abortion, $14 \%$ had preterm PROM and $14 \%$ preterm labour. Term PROM was the outcome in 5.7\% and cervical injury occurred in $8.6 \%$.

Conclusion: Cervical cerclage is beneficial for pregnancy with cervical insufficiency and hence placement of cervical cerclage can reduce early pregnancy loss.

JOPSOM 2020; 39(2): 70-73

https://doi.org/10.3329/jopsom.v39i2.53168

Keywords: Cervical Cerclage, Cervical Incompetence, Benefits, Pregnancy Outcome.

1. Senior Consultant, Department of Obstetrics and Gynaecology, Centre for Woman and Child Health, Jamgora, Ashulia, Dhaka.

2. Junior Consultant, Department of Obstetrics and Gynaecology, Centre for Woman and Child Health, Jamgora, Ashulia, Dhaka

3. Associate Professor, Department of Obstetrics and Gynaecology, Marks Medical College \& Hospital, Dhaka

4. Junior Consultant, Department of Obstetrics and Gynaecology, Centre for Woman and Child Health, Jamgora, Ashulia, Dhaka

5. Assistant professor, Department of dermatology, Dhaka Medical College \& Hospital, Dhaka

6. Associate professor, Virology, Department of Parasitology, NIPSOM
\end{abstract}

Correspondence: Dr. Anjuman Ara. Email: anjumanrita@gmail.com

\section{INTRODUCTION}

Cervical incompetence is a risk factor for adverse pregnancy outcome and can cause habitual abortion during 16-28 weeks. ${ }^{1}$ Its incidence varies between $0.05 \%$ and $2 \%$ of the obstetric population, but in women with a history of recurrent mid-trimester losses, it is estimated to occur in $8 \%$ of cases. ${ }^{(2)}$ To solve cervical insufficiency, surgical cerclage of the cervix has been traditionally used for more than 50 years, since it was first applied by Shirodkar and McDonald. Cervical cerclage involves suturing the cervix with a purse type stitch to keep it closed during pregnancy. ${ }^{3}$ Cervical cerclage is an effective method to mechanically prevent the cervix from further dilation. It is also the cornerstone of the treatment of women with an obstetrical history of premature birth and a shortened cervix on ultrasound and history of cervical insufficiency. ${ }^{4}$ Main indications of cervical cerclage are previous second trimester pregnancy loss or delivery that occurred with few or no contractions and cervical trauma or injury leading to cervical incompetence. ${ }^{3}$ The effectiveness of cervical cerclage in women with cervical incompetence using McDonald procedure increased the rate of term deliveries to $95.4 \%$. The mean gestational age of delivery was 35 weeks. ${ }^{5} 7.5 \%$ of miscarriages, $18.7 \%$ of premature deliveries, $73.7 \%$ of term deliveries and $85.1 \%$ of foetal survival rate (good Apgar score) were 
observed after cervical cerclage in patients having sonographically incompetent cervix. ${ }^{6}$

\section{METHODS}

This is an observational study conducted on 35 patients with cervical insufficiency diagnosed by obstetric history, clinical examination and sonographic cervical assessment. Eligible patients underwent a transvaginal ultrasound scan to confirm cervical length of less than $3 \mathrm{~cm}$ or dilatation of internal os $\geq 0.8 \mathrm{~cm}$ in the current pregnancy.

\section{RESULTS}

\section{Obstetrical Characteristics of the patients}

Among 35 patients, 20 were between 20-29 years and 15 were between 30-39 years. All were booked cases. $43 \%$ of cases were $4^{\text {th }}$ gravida, $37 \% 3^{\text {rd }}$ gravida and $20 \% 2^{\text {nd }}$ gravida. In $21(60 \%)$ cases cervical cerclage was given at 12-16 weeks of gestation, in 12 (34\%) cases between 17-20 weeks in $2(6 \%)$ cases between 21-24 weeks. In $20(57 \%)$ cases cerclage was given electively and in 15 (43\%) on emergency basis. The post-operative period was uneventful in 32 (91\%) cases and $3(8.6 \%)$ cases had lower abdominal pain.

Table 1: Obstetrical Characteristics of the study subjects $(n=35)$

\begin{tabular}{|c|c|c|}
\hline Attributes & Frequency & $\begin{array}{c}\text { Percentage } \\
(\%)\end{array}$ \\
\hline Age (years) & & \\
\hline $20-29$ & 15 & 43 \\
\hline $30-39$ & & 20 \\
\hline Gravida & 7 & 37 \\
\hline $2^{\text {nd }}$ & 13 & 43 \\
\hline $3^{\text {rd }}$ & 15 & 60 \\
\hline $4^{\text {th }}$ & 21 & 34.3 \\
\hline Gestational age at cerclage (weeks) & 12 & 5.7 \\
\hline $12-16$ & 2 & \\
\hline $17-20$ & & 57.1 \\
\hline $21-24$ & 20 & 42.8 \\
\hline Type of cerclage & 15 & 91.4 \\
\hline Elective & 32 & \\
\hline Emergency & 3 & \\
\hline Post-operative condition (48 hours) & & \\
\hline Good & & \\
\hline Lower abdominal pain & & \\
\hline
\end{tabular}

The mean pregnancy prolongation following cerclage was 17 weeks. Three (8.6\%) delivered between 28-32 weeks, $10(29 \%)$ between 33-36 weeks and $18(51 \%)$ at term. 24 (69\%) delivered by LUCS while 7 (20\%) vaginally. Due to maternal complications abortion was 4 (11\%), 5 (14\%) had preterm PROM, 5 (14\%) had preterm labour, 2(6\%) term PROM and 3(9\%) cervical injury during vaginal delivery. 
Table 2: Distribution of study subjects by maternal outcome

\begin{tabular}{|l|l|l|}
\hline \multicolumn{1}{|c|}{ Attributes } & Frequency & Percentage \\
\hline $\begin{array}{l}\text { Pregnancy prolongation following cerclage } \\
\text { (wks) }\end{array}$ & \multicolumn{2}{l|}{} \\
\hline $\begin{array}{l}\text { Mean } \pm \text { SD } \\
\text { Range (min, max) }\end{array} 17.0 \pm 6.7$ & & \\
\hline Gestational age of delivery & \multicolumn{2}{l|}{} \\
\hline $28-32$ & 3 & 8.6 \\
\hline $33-36$ & 10 & 29 \\
\hline Term & 18 & 51 \\
\hline Mode of delivery & & 20 \\
\hline NVD & 7 & 69 \\
\hline LUCS & 24 & 11 \\
\hline Maternal complications & 4 & 14 \\
\hline Abortion & 5 & 5.7 \\
\hline Preterm PROM & 5 & 8.6 \\
\hline Preterm labour & 2 & 14 \\
\hline Term PROM & & \\
\hline Cervical injury & & \\
\hline
\end{tabular}

\section{Distribution of study subject by foetal outcome}

In case of foetal outcome $89 \%$ survived up to 28 days of age. Eighteen (51\%) delivered at term and $13(37 \%)$ preterm (before 37 weeks of gestation). Of these 31 babies who survived $18(58 \%)$ babies were normal birth weight and 13 (42\%) were low birth weight.

Table 3: Distribution of study subject by foetal outcome

\begin{tabular}{|l|c|c|}
\hline Foetal outcome & Frequency & Percentage \\
\hline Alive $(\mathrm{n}=35)$ & 31 & 89 \\
\hline Term $(\mathrm{n}=35)$ & 18 & 51 \\
\hline $\begin{array}{l}\text { Low birth weight } \\
(\mathrm{n}=31)\end{array}$ & 13 & 42 \\
\hline Normal birth weight & 18 & 58 \\
\hline
\end{tabular}

\section{DISCUSSION}

Cervical cerclage is applied to prevent delivery and hence the complications of preterm delivery. In this study we evaluated the efficacy and outcomes of cerclage placement. We found patients can benefit from cerclage placement as the complication rate is low and the prognosis is good even with premature cases. In $20(60 \%)$ cases cervical cerclage was given in between 12-16 weeks' gestation, 12 (5.7\%) cases 21-24 weeks. The mean pregnancy prolongation following cerclage was 17 weeks. Eighteen (51\%) patients delivered at term, $13(37 \%)$ had preterm deliveries between 28-36 weeks and in 4 cases pregnancy loss occurred. This differs from another descriptive cross-sectional study ${ }^{7}$ over a 2 -year period on patients with 2 or more recurrent mid-trimester abortions or preterm deliveries. They reported $74 \%$ term deliveries after application of cervical cerclage, $19 \%$ premature deliveries and $7.5 \%$ miscarriages. Another study demonstrated $76 \%$ term deliveries, $12 \%$ of preterm deliveries and $10 \%$ of abortions. ${ }^{8}$ In our study $18(51.4 \%)$ had birth weight of $\geq 2.5 \mathrm{~kg}$ which shows that cervical cerclage improves neonatal survival and decrease perinatal morbidity. This has 
also been demonstrated in a study conducted in $2004^{9}$ which demonstrated $71 \%$ of cases having birth weight of $>2.5 \mathrm{~kg}$. This difference from our study may be due to the fact that our population had a lower socioeconomic status.

\section{CONCLUSION}

Cervical insufficiency is an important cause of early pregnancy loss. Cervical cerclage is an effective method to treat cervical insufficiency and hence to improve pregnancy outcome.

\section{REFERENCES}

1. Lash AF, Lash SR. Habitual abortion; the incompetent internal os of the cervix. Am J Obstet Gynecol 1950;59(1):68-76.

2. Brown R, Gagnon R, Delisle MF. MATERNAL FETAL MEDICINE COMMITTEE. Cervical insufficiency and cervical cerclage. J Obstet Gynaecol Can 2013;35(12):1115-1127.

3. Yassaee F, Mostafaee L. The role of cervical cerclage in pregnancy outcome in women with uterine anomaly. J Reprod Infertil 2011;12(4):277-9.

4. Owen J, Hankins G, Iams JD, Berghella V, Sheffield JS, Perez-Delboy A, et al. Multicenter randomized trial of cerclage for preterm birth prevention in high-risk women with shortened midtrimester cervical length. Am J Obstet Gynecol 2009;201(4):375.e1-8.

5. Lotgering FK, Gaugler-Senden IP, Lotgering SF, Wallenburg HC. Outcome after transabdominal cervicoisthmic cerclage. Obstet Gynecol. 2006;107(4):779-84.

6. Shennan A, Jones B. The cervix and prematurity: aetiology, prediction and prevention. Semin Fetal Neonatal Med 2004;9(6):471-9.

7. Shamshad, Mustajab Y, Jehanzaib M. Evaluation of cervical cerclage for sonographically incompetent cervix in at high risk patients. J Ayub Med Coll Abbottabad. 2008;20(2):31-4.

8. Celen S, Simsek Y, Ozyer S, Sucak A, Kaymak O, Turkcapar F, et al. Effectiveness of emergency cervical cerclage in patients with cervical dilation in the second trimester. Clin Exp Obstet Gynecol 2011;38(2):131-3.

9. Ezechi OC, Kalu BK, Nwokoro CA. Prophylactic cerclage for the prevention of preterm delivery. Int J Gynaecol Obstet. 2004 Jun;85(3):283-4. 